Bangladesh Journal of Anatomy January 2011, Vol. 9 No. 1 pp 13-20

\title{
Evolution in the Presentation of Developmental Anatomy and Genetics in a Commonly Recommended Developmental Anatomy Book Through Analyses its 'Preface's
}

\author{
Md. Mesbah Uddin ${ }^{1}, K_{\text {Khondkar Manzare Shamim² }}^{2}$
}

\begin{abstract}
Context: Medical education is a dynamic process and is changing constantly. More and more information is being dealt with everyday. Innovations are being in introduced in teaching-learning methods and tools. As an essential part of undergraduate medical education, the teaching \& learning of Developmental Anatomy and Genetics have also gone through remarkable changes in recent years. Some shifts in interest and approach as well in presentation patterns can easily be noticed in the Developmental Anatomy books through their editions. Methodological probing into the situation would bring to light the specific aspects of the issue and benefit the curriculum planners and teachers of Developmental Anatomy in bringing about necessary changes in running the undergraduate courses.
\end{abstract}

Study design: A descriptive observational study involving qualitative analyses.

Place and period of study: Department of Anatomy, Bangabandhu Sheikh Mujib Medical University (BSMMU), Dhaka, between January 2008 to December 2008.

Materials: The 'Preface's of all ten editions of a commonly recommended Developmental Anatomy book ('Langman's Medical Embryology').

Methods: The 'Preface's were analysed qualitatively to identify the information and explanations provided and comments made by their author/editor on the approaches taken and the means applied in the books in selecting and presenting topics, text and illustrations. The observations were organised into specific 'theme's.

Results: Twelve 'theme's could be identified from the analyses of the 'Preface's of all ten editions of a commonly recommended Developmental Anatomy book (Langman's Medical Embryology). These include special emphasis in the books on the maintenance of conciseness of the textbooks, on incorporation of new information, on the importance of genetics including molecular regulation and also on the clinical aspects of Developmental Anatomy and Genetics. Addition and improvement regarding illustrations are also evolved remarkably.

Conclusion: Incorporating the findings of the present study with the modern ideas and trends in teaching and assessment in Developmental Anatomy and Genetics in the renowned universities of the world, as evident from the available literature, suggestions could be formulated on improving the methods of teaching and assessment in Developmental Anatomy and Genetics in Bangladesh.

Key words: Developmental Anatomy Book, Preface, Theme.

Introduction:

Medical education has entered a new era at all levels, led by changes in the undergraduate curricula, and medical educators seeking for an answers to what changes are necessary to prepare

1. Assistant Professor, Department of Anatomy, Kumudini Women's Medical College, Tangail.

2. Professor and Head, Department of Anatomy, Bangabandhu Sheikh Mujib Medical University, (BSMMU), Dhaka.

Correspondence: Dr. Md. Mesbah Uddin. future physicians for practice. The biggest questions facing medical education as the twenty-first century approaches are: what should be the aims of medical education? What should be taught, where and by whom? And how can we ensure that the curriculum evolves continuously in response to ever-changing external environment? ${ }^{1}$

Anatomy is one of the major foundation sciences in the medical curriculum. Developmental Anatomy and Genetics are two important branches of Anatomy 
that are developing day by day. The concept of teaching-learning as well as the assessment system is also changing in the field of Developmental Anatomy and Genetics. There are many opinions in the world literature about how much of Developmental Anatomy and Genetics should be taught and which issues should be addressed in the teaching of these two branches of Anatomy in medical curricula.

In the present days, the central challenge for teachers of Developmental Anatomy is how to convey to their students the essential picture of human development according to the recent trends and concepts. In an attempt to understand the recent trends, textbooks are supposed to be good indices. Carlson ${ }^{2}$ believes that "textbooks continue to be a main stay of many medical courses. Therefore, it may be assumed that a good Developmental Anatomy book would reflect the important aspects of the recent global trends in Developmental Anatomy and Genetics teaching-learning. So analysing the 'Preface's of the book may be a good idea to get the information, explanations and comments from the author/editor on these approaches and means in a nutshell.

\section{Materials and Methods:}

The present study was a descriptive observational study involving qualitative analyses. It was carried out to assess the evolution of the presentation of a commonly recommended Developmental Anatomy textbook regarding the approaches taken and means applied in dealing with Developmental Anatomy and Genetics. Preferably, 'Preface's of the all available editions of a commonly recommended Developmental Anatomy textbook was considered for the study. Finally, a book popularly known as 'Langman's Medical Embryology' textbook was chosen for the analyses of their 'Preface's. The overall study plan is shown in Figure 1. The study was carried out in the Department of Anatomy, Bangabandhu Sheikh Mujib Medical University (BSMMU), Dhaka, from January, 2008 to December, 2008.

Operational definitions for the analyses of 'Preface's

\section{Preface}

A 'Preface' is defined as an 'Introduction to a book'. ${ }^{13}$ In the present study, the introductory notes of each of the 11 selected Developmental Anatomy books designated as 'Preface' were analysed.

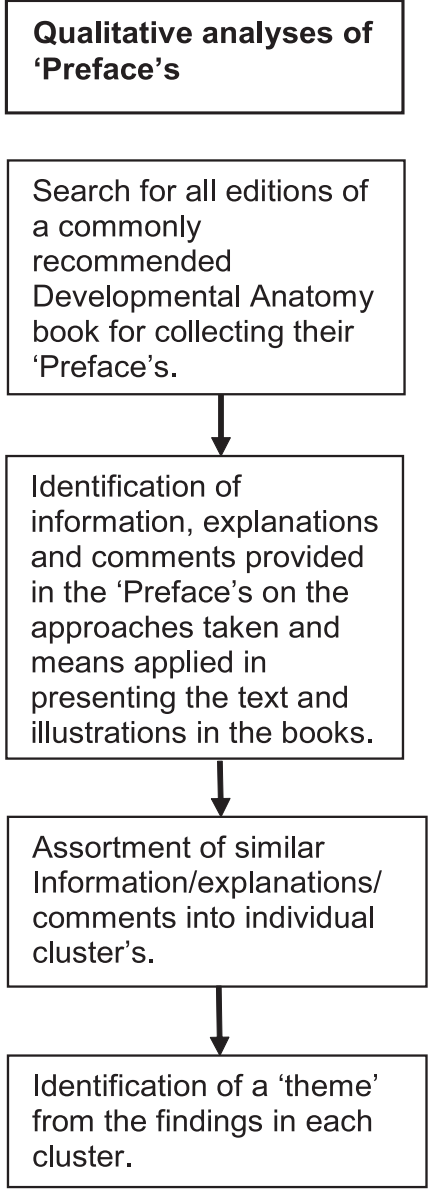

Fig. -1 The overall study plan.

Table-I

List of the ten editions of Langman's Medical Embryology ${ }^{3-12}$ with corresponding years of publications the 'Preface's of which were analysed in the present study

\begin{tabular}{lc}
\hline Number of edition & Year of publication \\
\hline $1^{\text {st }}$ & 1963 \\
$2^{\text {nd }}$ & 1969 \\
$3^{\text {rd }}$ & 1975 \\
$4^{\text {th }}$ & 1981 \\
$5^{\text {th }}$ & 1985 \\
$6^{\text {th }}$ & 1989 \\
$7^{\text {th }}$ & 1995 \\
$8^{\text {th }}$ & 2000 \\
$9^{\text {th }}$ & 2004 \\
$10^{\text {th }}$ & 2007 \\
\hline
\end{tabular}

2. Cluster Similar information, explanations or comments that could be observed in the 'Preface's 
was/were termed as a 'cluster' from which one 'theme' could be identified. ${ }^{4}$

\section{Theme}

A 'theme' was defined as a statement expressing the essence of information, explanations or comments represented by a 'cluster'. ${ }^{14}$

\section{Operational definitions to see the evolution of presentation}

Decreased (D): The 'theme' is 'decreased' in amount from the previous edition.

Example: "I have tried to keep this edition as concise and short as the first one. Unfortunately, I have not been quite successful". 4

New (N): The 'theme' is 'newly' introduced in the particular edition.

Example: "New to this edition, a glossary of key terms located in the back of the book" (Langman's Medical Embryology 1997, Preface).

Repeated (R): The 'theme' is 'repeated' in the particular edition.

Example: "This theme (conciseness) is preserved in the present edition" (Langman's Medical Embryology 1989, Preface).

Modified (M): The 'theme' is 'modified' in the particular edition.

Example: "The medically important congenital abnormalities are now interwoven with normal development" (Langman's Medical Embryology 1981, Preface).
Increased (I): The 'theme' is 'increased' in amount from in the previous edition.

Example: "Increased numbers of scanning electron micrographs have been included" (Langman's Medical Embryology 1985, Preface).

\section{Results:}

Qualitative analyses of the 'Preface's of all editions of a commonly recommended Developmental Anatomy book ('Langman's Medical Embryology') regarding the approaches taken and means applied in dealing with Developmental Anatomy and Genetics were done. Twelve 'theme's could be identified from the comments and claims made by the author/editor as shown in Table II. Edition-wise evolutions of the main 'theme's are shown in Figure 2.

The figure shows that there are few themes ('incorporation of recent information', 'emphasis on clinical aspects', and 'emphasis on illustrations') which appeared almost in each edition of the book. Emphasis and the importance on these themes has also been increased both in respect of quality and quantity from one edition to the subsequent edition. Although, a number of themes ('maintenance of conciseness', 'emphasis on molecular aspects', 'emphasis on illustrations', 'provision of summary', 'provision of CD ROM' and 'provision of online addresses') gain importance in a gradually increasing way in the last few editions of the books. These observations have been shown by the use of colour gradient (from light colour to dark colour).

Table II

The 'theme's emerging from the observations made through the analyses of 'Preface's of a commonly recommended Developmental Anatomy book (Langman's Medical Embryology) on the approaches taken and means applied in dealing with Developmental Anatomy and Genetics

\begin{tabular}{llc}
\hline SI. no. & Theme & No. of editions $(\mathrm{n}=10)$ \\
\hline 1. & Emphasis has been given on the maintenance of conciseness of the book & 5 \\
2. & Attempts have been made to incorporate contemporary and new information on & \\
& Developmental Anatomy and Genetics & 6 \\
3. & Molecular aspects of genetics related to development have been highlighted & 4 \\
4. & Emphasis has been given on clinical aspects of Developmental Anatomy and Genetics & 7 \\
5. & Illustrations have been added and/or improved & 10 \\
6. & Tables/charts have been added & 3 \\
7. & Summary has been provided for reviewing the key points & 3 \\
8. & Glossary has been added for quick references & 1 \\
9. & Importance has been attached to self assessment by putting self assessment questions \\
10. & Online addresses have been attached for further information & 3 \\
11. & CD ROM has been provided with the book & 2 \\
12. & Change has been made in the title of the book & 2 \\
\hline
\end{tabular}




\begin{tabular}{|c|c|c|c|c|c|c|c|c|c|c|c|}
\hline \multirow[t]{2}{*}{ SI } & \multirow[t]{2}{*}{ Theme* } & \multicolumn{10}{|c|}{ Edition-wise presentation } \\
\hline & & 1st & 2nd & $3 r d$ & 4th & 5 th & 6th & 7 th & 8th & 9th & 10th \\
\hline 1 & $\begin{array}{l}\text { Maintenance of } \\
\text { conciseness }\end{array}$ & & D & $\mathrm{N}$ & & & $\mathrm{R}$ & & & $\mathrm{R}$ & $\mathrm{R}$ \\
\hline 2 & $\begin{array}{l}\text { Incorporation of } \\
\text { recent information }\end{array}$ & $\mathrm{N}$ & & I & & I & I & & & I & I \\
\hline 3 & $\begin{array}{l}\text { Emphasis on } \\
\text { molecular aspects }\end{array}$ & & & & & & & D & 1 & 1 & 1 \\
\hline 4 & $\begin{array}{l}\text { Emphasis on } \\
\text { clinical aspects }\end{array}$ & $\mathrm{N}$ & & I & M & & & I & I & I & $\mathrm{R}$ \\
\hline \multirow{2}{*}{5} & \multirow{2}{*}{ Use of illustrations } & \multirow{2}{*}{$N$} & M & M & M & \multirow{2}{*}{ I } & \multirow{2}{*}{ I } & \multirow{2}{*}{ I } & \multirow{2}{*}{ I } & \multirow{2}{*}{ I } & M \\
\hline & & & I & I & I & & & & & & I \\
\hline 6 & $\begin{array}{l}\text { Use of } \\
\text { tables/charts }\end{array}$ & & & & $N$ & 1 & I & & & & \\
\hline 7 & $\begin{array}{l}\text { Provision of } \\
\text { summary }\end{array}$ & & & & $\mathrm{N}$ & & & & & $\mathrm{R}$ & $\mathrm{R}$ \\
\hline 8 & Use of glossary & & & & & & & & & & $\mathrm{N}$ \\
\hline 9 & $\begin{array}{l}\text { Emphasis on self } \\
\text { assessment }\end{array}$ & & & & & & & $\mathrm{N}$ & & $\mathrm{R}$ & $\mathrm{R}$ \\
\hline 10 & $\begin{array}{l}\text { Provision of online } \\
\text { address }\end{array}$ & & & & & & & & & $\mathrm{N}$ & $\mathrm{R}$ \\
\hline 11 & $\begin{array}{l}\text { Provision of CD } \\
\text { ROM }\end{array}$ & & & & & & & & & $\mathrm{N}$ & $\mathrm{R}$ \\
\hline 12 & $\begin{array}{l}\text { Changing the title } \\
\text { of the book }\end{array}$ & & & & & $N$ & & & & & \\
\hline
\end{tabular}

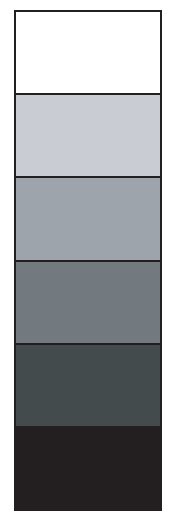

'Decreased' in amount from a previous edition.

Not mentioned in the particular edition.

'Newly' introduced in the particular edition.

'Repeated' in the particular edition.

'Modified' in the particular edition.

'Increased' in amount from the previous edition.

Fig.-2: Edition-wise evolution of the 'theme's emerging from the observations made through the analyses of 'Preface's of a commonly recommended Developmental Anatomy book (Langman's Medical Embryology) on the approaches taken and means applied in dealing with Developmental Anatomy and Genetics. The 'theme's are based only on specific mentions in the 'Prefaces' rather than on any assumption made by the present researcher.

*The twelve theme's mentioned here are the shortened versions of the twelve theme's presented in Table II respectively. 


\section{Discussions:}

The present thesis work was intended to assess how the presentation style of a commonly recommended Developmental Anatomy textbook (Langman's Medical Embryology) has evolved through its ten editions. This was done by analyzing its' ten Prefaces. Although Developmental Anatomy/ Embryology has always been an integral part of our undergraduate medical courses, the attitude towards the subject has been very different from that towards Regional Anatomy, Microscopic Anatomy and Neuroanatomy. Similar, or probably somewhat / worse in the situation with Genetics. The use of teaching-learning materials in Developmental Anatomy or Genetics is not well defined, wellthought or uniform. The present study may have been able to make some important points and create an evidence-based foundation upon which positive steps may be taken in future towards fulfilling the objectives set in the undergraduate curriculum. The analyses of the 'Preface's of all ten editions of the textbook, 'Langman's Medical Embryology' revealed twelve main 'theme's regarding the approaches taken and means applied in the books in presenting Developmental Anatomy and Genetics. The edition-wise evolution of each theme also could be traced.

\section{On maintenance of conciseness of the textbooks}

Time allocation for the basic sciences in medical course curriculum has been reduced in recent years throughout the world. There has been a good amount of decrease in the time allotted to studying anatomy in medical courses.15 Therefore; the traditional place of Anatomy in the medical curricula is being seriously challenged. And its impact, not surprisingly, is also reflected in the teaching-learning of Developmental Anatomy and Genetics. The authors/editors of Developmental Anatomy books around the world are bound to write/edit their books keeping this change in mind. They have to make their books concise without ignoring the important and updated information. Medical information grows exponentially. Thus students face a rapidly growing body of scientific knowledge. It becomes essential, therefore, to provide texts that present a clear, concise and timely overview of a subject.
It is observed from the 'Result's chapter of this thesis that maintenance of conciseness has received importance in the 'Preface's of at least five editions (2nd, 3rd, 6th, 9th and 10th) of 'Langman's Medical Embryology'. Langman4 realised that "a new edition usually means adding an extra hundred pages to the original text", "I have tried to keep this edition as concise and short as the first one", he added. Personal experience of the present researcher suggests that there is considerable amount of confusion among the anatomists of the country regarding how 'concise' should Developmental Anatomy between incorporation of newer information and understanding and keeping the amount of study material manageable in a tough job.

Medical schools across the world employ a wide range of styles of teaching for students' learning of Developmental Anatomy and Genetics, with variable levels of integration with other subjects. Most medical schools teach Developmental Anatomy integrated with Gross Anatomy. Developmental anatomy is a powerful adjunct to an in-depth understanding of gross anatomical pattern. Teaching Developmental Anatomy in conjunction with adult anatomy makes both easier to comprehend and more likely to be retained. ${ }^{16}$ The later stages of organogenesis should be taught in conjunction with the study of the adult Anatomy of these same structures or regions. ${ }^{17}$

In addition to the above mentioned integration, various new teaching methodologies such as team based learning (TBL), problem based learning ( $P B L)$ and computer assisted learning (CAL), are being adopted in the medical institutions of different countries to compensate the reduced time allocation in the course curriculum. Learning of Anatomy is no exception in this regard. According to McCrorie, 18 "problem based learning helps the clinical/ preclinical divide to disappear". Even some of our neighboring countries are trying to adopt some of the new systems. Some of the conventional medical schools in India are incorporating components of $\mathrm{PBL}$ in Anatomy, in their existing conventional curricula. ${ }^{19}$ Majority of students of Pakistan consider PBL as an efficient method of learning. ${ }^{20}$ The strategy (TBL) has eliminated didactic lectures and incorporated small-group active learning. ${ }^{21}$ It 
has been reported ${ }^{22}$ that, the majority of American medical colleges are adopting small group discussion, seminars on specific subjects, problem solving by students etc, thus exposing the students to the clinical situation at an early stage.

In the United Kingdom, during the 1990s, the General Medical Council issued guidelines to medical schools which stated that "undue emphasis on details was not required". ${ }^{15}$ Older $^{23}$ also suggested "to reduce overall content, didactic lectures and mechanical rote memorisation". In a study $^{24}$ it has been showed that, Developmental Anatomy should be taught in small group tutorials and practicals with the help of models, charts and/ or multimedia after scheduled didactic lecture of a particular topic to have better understanding of the specific topic.

The Internet has revolutionised the learning of many subjects. Many institutions are laying emphasis on web-based learning. It is understandable that Bangladesh is not yet equipped for such web-based education. However, materials downloaded from online sources, especially figures, may well be utilized for clarifying the concepts of Developmental Anatomy and Genetics to students.

Digital animation has also gone through a revolution in recent years. ${ }^{25}$ Many textbooks have created support sites on the web which help to download updates, videos, and animations. Even CD-ROMs are provided with the textbooks. Lip et $\mathrm{al}^{26}$ have also emphasised on the use of animation in Developmental Anatomy. According to them, "animation is particularly powerful as it is hard for the student to visualize from text and pictures alone".

\section{On the importance of molecular aspects of Developmental Anatomy}

The importance of molecular regulation of development is gaining noticeable importance in recent years. Although in the seventh edition of Langman's Medical Embryology the molecular aspects of development was given minimal importance to lay emphasis on clinical aspects, its importance has been much appreciated in the later editions. In the last (10th) edition, Sadler has added a completely 'new' chapter on 'Molecular Biology' to the book. Besides, almost every chapter has got a description of the molecular regulation relevant of development to clarify the underlying mechanisms of development.

Many of the stakeholders of Developmental Anatomy and Genetics think that molecular regulation of development should get due emphasis at the medical undergraduate level. In an effort to address Developmental Anatomy properly, the Educational Affairs Committee of the American Association of Clinical Anatomists (AACA) has developed a Clinical Anatomy curriculum in Developmental Anatomy. One of the three aspects is to highlight molecular and genetic mechanisms. ${ }^{27}$ The main challenge for curriculum planners in medical embryology will be to correlate adequately structural changes of the embryo with the dramatic surge in molecular and experimental data, and to present an overview of the clinical relevance of such data. $^{28}$

Though time allocation for Developmental Anatomy and Genetics has been decreased in the curriculum, yet at least some basic ideas such as fate map, embryo folding, somite differentiation have to be explained to the students which will create interest among them to learn this topic. Moreover, how a single gene defect can cause congenital anomalies can also be explained to the students. At least one or two lecture classes might be arranged for molecular regulation of development.

On the importance of clinical aspects of Developmental Anatomy and Genetics

From the medical perspective, one of the major justifications for studying Developmental Anatomy is to provide a basis for understanding the genesis of birth defects. Structural descriptions are seldom fruitful without adequate functional and clinical correlates. The trends in the recent Developmental Anatomy books are that of being more clinically oriented.

While analysing the 'Preface's of the ten editions of 'Langman's Medical Embryology' textbook, it has been observed that in the earlier editions of the book there was a separate chapter on the clinical aspects of Developmental Anatomy where the issue of abnormal development was discussed. Subsequently, clinical aspects of abnormal 
development have been incorporated in each relevant chapter. The number of clinical photographs has been gradually increased and texts on clinical portions have been highlighted with the use of boxes. All these have been done only to make the readers realise the importance of abnormal development alongside the normal development. Besides, some clinical problems have been mentioned at the end of each chapter in the form of questions, the answers of which have been provided at the end of the book.

It cannot be said that teachers of Developmental Anatomy of medical colleges of Bangladesh are ignoring the clinical aspects of Developmental Anatomy. At the same time, we are not confident that we are presenting the importance of clinical aspects in the proper way. Teaching developmental anomalies should not address just names, but rather integrate the anomalies with corresponding developmental processes. Thus, developmental anomalies should be taught during, rather than at the end of, teaching normal development of a particular organ or system. Lastly, it may be suggested that the teaching-learning of Developmental Anatomy and Genetics should be approached in such a way that the clinical aspect is understood being related with its structure and this approach should be reflected properly in our assessment system.

On the importance of illustrations in Developmental Anatomy and Genetics

The understanding that both Developmental Anatomy and Genetics are visual subjects (the former possibly being more so) is essential for proper understanding of the subjects. ${ }^{29}$ These two complex subjects must be simplified with suitable illustrations. The evolution of illustration during analyses of 'Preface's of 'Langman's Medical Embryology' is also noticeable. New illustrations have been added to almost every edition of the book. Moreover, many of the illustrations have been improved or modified over the last four and half decades.

Figures are like patients to a doctor. There is long term impact of using illustrations in teaching and learning process and it also produces better understanding level. It is understandable that in availability, an adult cadaver and an embryo/fetus are way apart. Presentation of intrauterine features is therefore much more dependent on instructional tools like models and illustrations. So, in our country, teaching-learning of Developmental Anatomy and Genetics should be more illustration oriented and this must have reflections in both oral and practical examinations. If the students' awareness to the usefulness of figures and interest in figures has to be elevated, use of figures in the assessment examination should be the most efficient and practical way to do so.

\section{On incorporation of self assessment questions in the textbooks}

Self assessment has been encouraged by Sadler ${ }^{12}$ by providing problems at the end of each chapter. Sadler ${ }^{12}$ believes that these problems test a student's ability to apply the information covered in a particular chapter.

\section{References:}

1. Towle A. The aims of the curriculum: education for health needs in 2000 and beyond. In: B. JOLLY, AND L. REES, eds. Medical education in the millennium, 1998.

2. Carlson BM. Patten's foundations of embryology. $6^{\text {th }}$ ed. New York: Mc Graw-Hill, 1988.

3. Langman J. Medical Embryology. Baltimore: The Williams and Wilkins Company, 1963.

4. Langman J. Medical Embryology. $2^{\text {nd }}$ ed. Baltimore: The Williams and Wilkins Company, 1969.

5. Langman J. Medical Embryology. $3^{\text {rd }}$ ed. Baltimore: The Williams and Wilkins Company, 1975.

6. Langman J. Medical Embryology. $4^{\text {th }}$ ed. Baltimore: The Williams and Wilkins Company, 1981.

7. Sadler TW. Langman's Medical Embryology. $5^{\text {th }}$ ed. Baltimore: Williams \& Wilkins, 1985.

8. Sadler TW. Langman's Medical Embryology. $6^{\text {th }}$ ed. Baltimore: Williams \& Wilkins, 1989. 
9. Sadler TW. Langman's Medical Embryology. $7^{\text {th }}$ ed. Baltimore: Williams \& Wilkins, 1995.

10. Sadler TW, Langman's Medical Embryology. $8^{\text {th }}$ ed. Philadelphia: Lillpincott Williams \& Wilkins, 2000.

11. Sadler TW. Langman's Medical Embryology. $9^{\text {th }}$ ed. Philadelphia: Lillpincott Williams \& Wilkins, 2004.

12. Sadler TW. Langman's Medical Embryology. $10^{\text {th }}$ ed. New Delhi: Lillpincott Williams \& Wilkins, 2007.

13. Student's favourite dictionary. Preface, 1990. 993.

14. Amin NF. Recent trends in the presentation of cell biology and histology and their reflections in the written assessment at the medical undergraduate level in Bangladesh. Thesis (M Phil). Bangabandu Shiekh Mujib Medical University, 2008.

15. Patel KM, Moxham BJ. Attitudes of professional anatomists to curricular change. Clinical Anatomy, 2006.

16. Dalley AF. Integration of embryology and gross anatomy. The Faseb Journal Available at: http:/ /www.fasebj.org/ content/meeting.

17. Carlson BM. Embryology in medical curriculum. The Anatomical Record 2002.

18. McCrorie P. The place of the basic sciences in medical curricula. Medical Education, 2000. 594.

19. Nayak S, Ramnarayan K, Somayji N, Bairy $\mathrm{KL}$. Teaching anatomy in a problem based learning (PBL) curriculum, 2008.

20. Shankar PR. Basic sciences in south asia now and then: A personal perspective. South Asian Journal of Medical Education, 2008.
21. Vasan NS, Defouw DO, Holland BK. Modified use of team based learning for effective delivery of medical gross anatomy and embryology. Anatomical Sciences Education, 2008.

22. Baozhi S, Yuhong Z. Medical curricula in China and USA: a comparative study. Medical Teacher, 2003. 424.

23. Older J. Anatomy: a must for teaching the next generation, 2004. Available at: http:// www. Researchgate. Net/publication/ 8159923Anatomy.

24. Dutta SL, Singh C, Saxena SK. How to teach undergraduate embryology teachers perspective. Journal of the Anatomical Society of India 2006.

25. Shaffer $\mathrm{K}$. Teaching anatomy in the digital world, 2004. Available at: http:// content.Nejm.Org/cgi/content .

26. Lip G, Brien MO, Tanner A, Foley C, Grimson J. Teaching anatomy using multimedia, 2000. Available at: http://www.Tcd.Ie/tsmj./ 2000/ Anatomy.

27. American Association of Clinical Anatomists. 2000. Available at: http://www. Ncbi.NIm.Nih. Gov/pubmed.

28. Tavares I. The molecular metamorphosis of embryology: implications for medical education 2004. Available at: http://www3.interscience. Wiley.Com/cgi.

29. Nahar L. Suggesting documents for structuring the embryology and genetics oral- practical exams of the M Phil anatomy course at Bangbabandhu Sheikh Mujib medical university. Thesis (M Phil). Bangabandu Shiekh Mujib Medical University, 2005. 